Regis has sufficiently albeit too strongly covered the point of age. The luetic, gouty, rheumatic, traumatic and hereditary types occur at any age. The luetic cases resulting after the age of 65 , are of rather long duration. In three such cases, the patient reached the age of 73 , but each resided the whole period in an insane hospital. In three hereditary cases, occurring after 65 (one male, two females), of less duration ( 6 years); three sons were also afflicted at from 17 to 23 with paretic dementia. The sons died ere their parents from intercurrent complication due to trophic changes: the spinal symptoms were especially predominant. In epileptics who became paretic dements at the climacteric period the psychosis ran its usual course, and rarely lasted three years after its onset. In ataxics however, the remissions were frequent and protracted, but querulency existed.

The Hebrew race, as Spitzka $^{12}$ several years ago pointed out, seems to be peculiarly liable to this type. Heredity and lues prepare the soil which this psychosis attacks. Pure paretic dementia is, in my experience, rare with Hebrews. ${ }^{13}$

The forensic results of this type of paretic dementia, have already been shown. This psychosis constitutes at times no little financial danger to communities from the precipitation of parics.

\section{DISCUSSION OF ELECTRICAL EXECUTION.}

Read in the Section of Neurology and Medical Jurisprudence, at th Forty third annual meeting of the American Medical Association, held in Detroit, Mlch.. June, 1892.

\section{BY A. D. ROCKWELL, M.D.,} OF NEW YORK.

While I do not believe that the best use to which a man can be put is to kill him, yet all will agree that if the law will kill, let it kill decently. It is evident that the sentiment against hanging and in favor of some method quicker and less repulsive is strengthening and that other methods will sooner or later replace the rope everywhere. Mr. Edison while in Paris during the exposition gave his opinion so positively in regard to the efficiency of electricity that the medical section of the French Academy of Sciences aided by Marcel Duprez, a prominent electrician, have had the matter under careful investigation. There is always opposition and friction attending changes for the better, and this change has been no exception to the general rule. The whole tendency of our civilization is, however, in the direction of humane methods in dealing with criminals and that form of execution which is quickest and least repulsive should be adopted. It is a mathematical impossibility that any human being receiving in proper form a electrical current of lethal energy should appreciate even for a fraction of a second the slightest pain. It has been ascertained that the brain is onetwenty-fifth of a second in recognizing an impression, and one-twenty-eighth of a second in telegraphing that an impression has been received, and as nerve force travels only about 100 feet a second, while the velocity of the electric current is millions of times greater than this, the brain has absolutely no time to appreciate a sense of pain. As between electricity and certain other methods of capital punishment, it is not altogether clear that the former is the best that

12 Jour. of Nerv. and Mental Disease, 1880

13 Review of Insanity and Nervous Diseases, Vol. II. could be suggested. The guillotine and the garote are practically instantaneous and painless in their action and attended with only a fraction of the paraphernalia and expense of the method now adopted in New York State. There is, however, an apparent brutality attending both these methods that repels, and a mutilation and shedding of blood, which public opinion in this country seems unwilling to tolerate.

The action of poison is open to none of these objections, and it seems somewhat singular that it has not more strongly commended itself to the philanthropic mind seeking simpler and more humane methods in the legal taking of human life. But as between electricity and the rope there can, it seems to me, be no question. Let us suppose that it had been customary to execute by electricity instead of by hanging, and that some one in the supposed interests of humanity should suggest that the former method be abolished, and the latter substituted; that a method practically instantaneous and painless, unattended by mutilation and without any distressing outward manifestations of pain, be replaced by one which usually fails to extinguish life for ten or twelve minutes, which in many cases it is reasonable to believe is attended with torture, and where the convulsive manifestations are horrible to witness-such a suggestion could not have the slightest claim for serious consideration, and as a matter of fact would never be offered.

After the passage by the legislature of the State of New York, of the law substituting electricity for hanging in the execution of criminals, there arose a terrible storm of opposition that apparently had for its basis extensive commercial interests. It was claimed by the opponents of the new method, that electricity was by no means certain to destroy life without the infliction of great pain, and the popular mind was agitated by repeated assertions of the possibility and probability of repulsive disfigurement by the heat and chemical action that would necessarily be developed in the use of currents of such great power. To determine these points and to advise the State as to the best methods of procedure, a commission was appointed consisting of Dr. Charles Mac Donald, Chairman of the State Commission in Lunacy, Prof. L.H. Laudy of Columbia College, and the writer, who both at the Edison Laboratory and at the various prisons of the State, experimented largely upon animals, and tested many devices and methods for the application of the current. There could be no charge of cruelty in these investigations for in no single instance was there any evidence that the slightest pain was inflicted.

The largest animals, such as horses and a bull, instantly succumbed to an electric pressure of one thousand volts, while dogs and calves were as readily destroyed by five and six hundred volts.

But one impact of the current was found necessary, for death was instantaneous in every case.

Immediate examination after the opening of the circuit invariably failed to elicit the slightest respiration. or heart beat, and careful and persistent efforts at artificial respiration conducted by Dr. Fell of Buffalo with the latest and most approved appliances were without avail.

In view of the fact thus satisfactorily demonstrated that one thousand or at the most fifteen hundred volts would instantly kill any animal large or small, we very naturally inferred that any human being 
would succumb even more readily, but to make assurance doubly sure, it was recommended that not less than 1,500 or 2,000 volts be employed in the execution of criminals. To our great surprise therefore it was demonstrated at the first electrical execution, and confirmed in every subsequent attempt, that it was far more difficult to kill a man by electricity than any ordinary domestic animal however large. In the only execution which the writer attended, when four criminals were successively subjected to the electric stroke, the first contact of twenty seconds with a voltage of 1700 left its victim apparently lifeless with the exception of a slight fluttering of the pulse and what appeared to be a slight expiratory effort.

Because of these faint evidences of vitality it was decided then, and has been customary since to repeat the shock once and sometimes twice. That the victims were, however, in every instance so thoroughly devitalized by the first shock as to preclude the possibility of resuscitation, and that every vestige of consciousness was instantly obliterated, admitted of not the shadow of a doubt. In these cases a man's brain acts in two ways, and I should say that the reasons for this increased strength of current necessary in the case of a human being were both psychical and physical. In the first place, the man knows what is coming, and every nerve and muscle is tense with involuntary resistance. There is a mysterious likeness between nervous force and electric force; not a resemblance exactly, but a something about each which science has yet to fathom.

I have no doubt that this nervous tension operates directly to impede the action of the electricity, while the secondary effect is physical. The body conducts electricity by virtue of its saline solutions.

Now fright drives the blood away from the surface to the central portions of the body.

When a man is placed in the chair he is necessarily terribly frightened, and the result is that the surface tissues are unnaturally dry, and hence inferior conductors. With an animal these influences do not prevail, but the most striking confirmation of the probable truth of this suggestion lies in the fact of the greater readiness with which life is extinguished in men from accidental contact with electrical energy.

Even where the contact has been incomplete and imperfect, linemen have been instantly killed with electrical potentials no greater than those employed in judicial executions. When a man thus accidentally comes in contact with the current, his will or nervous force is in a passive state and offers no resistance to the action of the current, while the surface of the body is usually flushed with the exertion of work, and in the highest state of conductivity. Notwithstanding the efforts of a united press to exaggerate results, no one who has once witnessed a properly conducted execution by electricity can fail to commend it as a most humane method as compared to hanging. Aside from the fact that a human life is being taken by violence, there is little in connection with the execution that is revolting to the senses. After the first convulsive movement as the current is received, every muscle is simply tense and motionless until the current is broken, when re laxation takes place and the man is to all intents dead.
It will be recollected that the press raised a great outcry against the use of electricity, not only because of its supposed inefficiency, but because of what was described as repulsive mutilation by burns and scalds. While the degree of heat generated, and the influence exerted upon the superficial tissues, varied in the different cases, according to the position of the electrodes and the density of the current near the points of contact, in no instance was there any such repulsive disfigurement as has been intimated, and in all but one or two the effects produced were so superficial and slight as to be unworthy of comment. It cannot be denied, however, that owing to the limited area through which the tremendous voltage required has to operate, and the immense resistance offered to its passage, there occurs a remarkable drop in potential and an astonishing development of heat, which without the exercise of the most intelligent and careful supervision might result in such severe burning as to bring under public condemnation a method which thus far commended itself to all eye witnesses.

But it is not voltage alone that kills, but its rate of expenditure in the body as expressed by ampères, and the time consumed in its expenditure as expressed by the volt amperre seconds indicating the nieasure of the heat developed during the action of the current. As stated by the distinguished electrical expert, W. J. Jenks, "none of these factors are well settled as yet in their relation to the energy actually required to cause instant and painless death. By death, I mean now not alone cessation of consciousness of a perfectly healthy human being in an interval too brief for thought to measure, and the establishment of conditions which produce gradual and final expenditure of the stored nervous energy of the brain and the subordinate centers of distribution of vital force-such as the pneumogastric nerve and the spinal cord. I mean also, total paralysis of all the vital organs, and of the nervous centers by which they are directly or indirectly vitalized, and by which the muscles of the extremities are actuated, so that when the current is broken there can be no reflex action of the muscles, such as would indicate the presence of residual life energy, or a possibility of its resuscitation."

The question which physicists must determine is how with a comparatively low voltage the same number of ampères that are expended upon the periphery and therefore in a measure lost, could be made to act exclusively on the centers of life and nervous activity, instantly devitalizing them, while leaving no outward manifestation of the terrific power employed.

It has been asserted that the subject of executions by electricity is one with which the physician should have nothing to do, and vigorous protests have been made against the propriety of allowing the subject of legal executions to be discussed in our medical societies.

In arguing that the function of the physician is to save life and not to be in any way connected with devices that destroy-it is forgotten that in one of the departments of our art, our noblest efforts are enlisted in taking, for the purpose of saving life; and when death is inevitable the physician is at hand to soften the transition from visible time to invisible eternity. When the law, therefore, decides that some new and better method be adopted in the disposition of those against whom its heaviest penalty 
has been decreed, who but the educated physician is 'intended to fulfil. The chairs in use really have to decide upon the humanity of such change, and fewer objectionable features than the one just menwho but he should be selected to advise the State as tioned, in that they conform to the ordinary shape to the proper technical methods of procedure.

Whatever is worthy in action is proper in discussion, and as one of the advisory commission, appointed by my State, in the interests of the best methods of execution by electricity, I have felt that our work was never along more truly professional lines, or more in the interests of humanity.

\section{ELECTRODES, AND THEIR APPLICATION IN ELECTROCUTION.}

Read in the Section of Neurology and Medical Jurisprudence, at the Forty-third Annual Meeting of the American Medical Association, held at Detroit, Mich., June, 1892

BY GEO. E. FELL, M.D., F.R.M.S.,

OF BUFFALO, N. Y.

So long as the death penalty is regarded by the law as a necessity, so long will electrocution be the most humane method of executing it. This statement is made only after the most careful observation, extending some years over this inquiry, and after having witnessed the execution of William Kemmler and Joseph L. Tice at Auburn, N. Y. The term "humane" in this connection has a wider application than is generally considered. In the execution of the death penalty, the carrying out of the saddest mandate the law requires of its officers, the sense of duty has nerved them to their work. Even should they feel that the law may be overstepping its bounds in taking human life, it must be conceded that for the good of the greatest number its behests must be carried out. It should be remembered that the ends of legal justice are usually reached by slow processes; that malice is not a factor in any proper judicial decision, but justice mainly, when the decisions are reached through honest legal process. These facts should and do go a great way towards supporting the executive officer in the discharge of the most trying ordeal which an officer is called upon to perform. Humanitarian factors in the execution of the death penalty enter not only into the effect upon the culprit, in the prevention of physical or mental suffering, but also to a marked extent upon the immediate executors of the law. Electrocution when properly carried out offers the readiest, least troublesome of preparation, least horrible and most humane method of carrying out the death penalty. While the results of the application of this method have heretofore demonstrated these statements to be true, as compared with other known methods, there is yet, I believe, chance for improvement in the methods utilized, so far as the application, at least, of the electrodes is concerned.

The electrodes first suggested, in the Harold P. Brown chair, which was described in the Kemmler inquiry, consisted of a sponge adjusted upon a plate of copper to fit upon the sole of each foot of the culprit, this forming a double electrode. The other, a somewhat similar contrivance or cap, of suitable metal, placed over the skull, with a rubber cap to fit tightly to retain the moisture in connection with the sponge. No special detail of application of moisture or fluid to wet the electrodes was devisedpossibly because the first chair built upon this plan (which now lies in the basement of Auburn Prison) was not considered suitable for the purpose it was and peculiarities of the chair commonly used.

The next arrangement, which was the Kemmler chair, provided one electrode to apply to the spine and to the upper portion of the skull, to carry out the suggestions I first made in connection with this subject, "that the apparatus to be used should be arranged to permit the current to pass through the centers of function and intelligence in the brain." (See Report of Commission to investigate and report the most humane and practical method of carrying into effect the sentence of death in capital cases, page 84.)

The last method of carrying into execution the death penalty by electricity, so far as the electrodes are concerned, was the application of a wet sponge to the thigh and the forehead of the culprit.

These three different applications of the electrodes may now be considered. It must be conceded that the objective organ, or organs, which must be influenced to produce the most rapid death, consist of the heart, the center of the circulatory, the brain and spinal cord, the centers of the nervous, systems. If this is conceded we think there should be no difficulty in arriving at the best location of the electrodes which will the most efficiently destroy the activity of these different portions of the organism. What should be taken into consideration, of course, is the extent of resistance offered by the tissues through which the current is passed, the desideratum being to apply the electrodes so as to offer a minimum of resistance together with a maximum of influence of the current upon the organs mentioned. The application of the electrodes to the soles of the feet calls for the passage of the current through the entire extent of the limbs before the vital organ, the heart, is affected by it. The application of the electrode to the thigh also presents a greater extent of tissue than is necessary, in my opinion, and in reality is not so satisfactory for other reasons. In fact both these methods prevent the greatest intensity of the current from being expended upon the heart. In other words, the conductor represented by the cross section of the whole body, cannot permit that intensity of current that would be presented were the lower electrodes applied more closely to the cardiac region. When it comes to the application of the electrodes to the head we will find that there is valid objection to the forehead electrode as used at Sing Sing, and in the case of Joseph L. Tice at Auburn. Understand, that we are endeavoring to find the best theoretical points of application of electrodes. We must admit, of course, that electrocution may be carried out successfully without placing the electrodes in theoretically the best positions. Given a sufficiently powerful electric current applied to the hands, or to any vital portion of the body, its influence is sufficiently powerful to destroy life. But what is desired is to do this in the best way from all standpoints, standpoints of convenience in application as well as of the completeness of the work with the absence of reflexes or distortions of the body, which might seem objectionable. As to the forehead electrode, it is only necessary to look at a longitudinal section of the encephalon or entire head to see that much of the current may be expended without influencing the cerebrum or the cerebellum, except through dissemination to the 